\title{
Targeted enhancement of the therapeutic window of L19-TNF by transient and selective inhibition of RIPK1-signaling cascade
}

\author{
Sheila Dakhel ${ }^{1}$, Tiziano Ongaro ${ }^{1}$, Baptiste Gouyou ${ }^{1}$, Mattia Matasci ${ }^{1}$, Alessandra \\ Villa ${ }^{1}$, Dario Neri ${ }^{2}$ and Samuele Cazzamalli ${ }^{1, *}$ \\ ${ }^{1}$ Philochem AG, Otelfingen $\mathrm{CH}-8112$, Switzerland \\ ${ }^{2}$ Department of Applied Biosciences, Swiss Federal Institute of Technology (ETH Zürich), CH-8093 Zurich, Switzerland \\ ${ }^{*}$ Corresponding author \\ Correspondence to: Samuele Cazzamalli, email: samuele.cazzamalli@philogen.com \\ Keywords: tumor targeting; antibody-cytokine fusions; targeted-tumor necrosis factor; EDB-fibronectin; intracellular RIPK 1-inhibitors \\ Received: August 05, $2019 \quad$ Accepted: October 19, $2019 \quad$ Published: November 19, 2019 \\ Copyright: Dakhel et al. This is an open-access article distributed under the terms of the Creative Commons Attribution License \\ 3.0 (CC BY 3.0), which permits unrestricted use, distribution, and reproduction in any medium, provided the original author and \\ source are credited.
}

\section{ABSTRACT}

Introduction: Cytokine-based products are gaining importance for cancer immunotherapy. L19-TNF is a clinical-stage antibody-cytokine fusion protein that selectively accumulates to tumors and displays potent anticancer activity in preclinical models. Here, we describe an innovative approach to transiently inhibit off-target toxicity of L19-TNF, while maintaining antitumor activity.

Methods: GSK'963, a potent small molecule inhibitor of RIPK1, was tested in tumor-bearing mice for its ability to reduce acute toxicity associated with TNF signaling. The biological effects of L19-TNF on tumor cells, lymphocytes and tumor vessels were investigated with the aim to enable the administration of TNF doses, which would otherwise be lethal.

Results: Transient inhibition of RIPK1 allowed to increase the maximal tolerated dose of L19-TNF. The protective effect of GSK'963 did not affect the selective localization of the immunocytokine to tumors as evidenced by quantitative biodistribution analysis and allowed to reach high local TNF concentrations around tumor blood vessels, causing diffused vascular shutdown and hemorrhagic necrosis within the neoplastic mass.

Conclusions: The selective inhibition of RIPK1 with small molecule inhibitors can be used as a pharmaceutical tool to transiently mask TNF activity and improve the therapeutic window of TNF-based biopharmaceuticals. Similar approaches may be applicable to other pro-inflammatory cytokines.

\section{INTRODUCTION}

The therapeutic benefit associated with PD-1 blockade in a growing number of cancer indications [1-3] has stimulated the search for alternative immunotherapy strategies, that may be complementary to the use of immune checkpoint inhibitors. Cytokines represent a group of small immunoregulatory proteins, some of which have been considered for cancer therapy applications [4]. Recombinant interleukin-2 has been shown to eradicate metastatic melanoma or renal cell carcinoma in a small proportion of patients, who are fit enough to tolerate the severe side-effects associated with cytokine treatment $[5,6]$. Recombinant tumor necrosis factor (TNF) in combination with melphalan has gained marketing authorization in Europe for the treatment of unresectable soft tissue sarcoma, in which TNF is administered through isolated limb perfusion procedure [7].

Recombinant cytokines may cause substantial toxicity at very low doses (sometimes less than $1 \mathrm{mg}$ per patient), thus preventing escalation to therapeutically active regimens. For example, the maximal tolerated dose (MTD) of TNF for systemic administration procedures was found to be $300 \mu \mathrm{g} / \mathrm{patient}$ [8]. The fusion of cytokine 
payloads with recombinant antibodies, capable of selective localization to the tumor, may represent a strategy for the improvement of the therapeutic index of cytokine-based biopharmaceuticals [9-12]. Potent and selective anticancer activity has been observed in mouse models of cancer (particularly for fusion proteins based on IL2, IL12 and TNF payloads) [13-15]. Two fusion proteins of the L19 antibody (specific to the alternatively-spliced EDB domain of fibronectin, a pan-tumoral antigen whose expression in normal tissues is limited to female reproductive organs) are currently being investigated in Phase III clinical trials in Europe and in the United States. L19-IL2 has shown initial signs of activity against various tumor entities, including metastatic melanoma [16-18]. L19-TNF and other TNF-based fusion proteins were found to be potently active against soft-tissue sarcoma and the fullyhuman fusion protein is currently being studied in pivotal trials in this indication, in combination with doxorubicin (NCT03420014, Eudract no. 2016-003239-38).

The targeted delivery of TNF causes a rapid and selective hemorrhagic tumor necrosis in mouse models of cancer [19-21] and in patients [22]. TNF also boosts the activity of NK cells and of CD8+ T cells, which are required in order to eliminate the minimal residual disease and lead to protective immunity in mice [21, 23]. However, TNF-based pharmaceuticals may cause toxicity, especially at early time points after intravenous administration, when the concentration in blood is highest. The most common side effects include a drop in blood pressure, flu-like symptoms, nausea and vomiting. These toxicities typically disappear when the blood concentration of the product falls below a critical threshold [24, 25]. It would be desirable to develop strategies that preserve the therapeutic activity of targeted TNF pharmaceuticals, while decreasing systemic toxicity [9].

L19-TNF and related products provide a therapeutic benefit which is mediated by the durable high local concentration, that can be reached within the tumor mass. We reasoned that, if we were able to transiently inhibit TNF activity in blood (following intravenous administration of the product), we should be able to minimize side effects and safely administer higher doses of the product. One way to achieve this goal may be represented by the administration of small molecule inhibitors of key components in the TNF signaling pathway, building up activity at the tumor site, while decreasing systemic toxicity. Receptor-interacting protein kinase 1 (RIPK1) inhibitors may be ideally suited for this purpose, since RIPK1 is a key mediator of TNF-induced inflammation and tissue degeneration [26, 27].

In this article, we report our findings on the combination of L19-hTNF (the clinical-stage fusion protein) or L19-mTNF (an analogue featuring murine TNF as therapeutic payload) with GSK'963, a selective RIPK1 inhibitor [28]. Combination therapy studies were also performed with ibuprofen, a non-steroidal anti- inflammatory drug, commonly used for the premedication of cancer patients undergoing cytokine treatment. The sequential administration of GSK'963 and L19-TNF did not inhibit the preferential accumulation of the antibodycytokine fusion in the neoplastic mass and the induction of hemorrhagic necrosis in the tumor. The combination treatment allowed to safely administer L19-TNF beyond the maximal tolerated dose, with retention of potent anticancer activity. By contrast, co-administration of L19-TNF and ibuprofen did not reduce body weight loss and treatment-related toxicity. The findings of this paper may be clinically relevant and may be applicable to other cytokine biopharmaceuticals. Combination regimens with judiciously-chosen small molecule inhibitors may allow to increase the maximal tolerated dose, thanks to a transient inhibition of signaling events in blood and in normal organs. A long residence time of the cytokine moiety within the tumor mass is less likely to be affected by the inhibitor, as small molecules are often cleared within minutes or hours.

\section{RESULTS}

\section{Production of L19-TNF fusion proteins and quality control}

L19-hTNF and L19-mTNF were produced in CHO cells and purified to homogeneity. The proteins, which form stable non-covalent homotrimers thanks to the TNF moiety (Figure 1A), were pure in SDS-PAGE analysis and eluted as single peak in gel-filtration (Figure 1B and 1C). Deconvolution of LC-MS profile allowed identification of the expected experimental masses for L19-mTNF and L19-hTNF, which were compatible with the predicted values in the absence of any protein glycosylation (Figure $1 \mathrm{D}$ and $1 \mathrm{E})$. Sequences of the fusion proteins are described in the Supplementary Information.

\section{RIPK1 inhibitors reduce in vitro potency of L19- TNF}

Small molecule inhibitors of RIPK1 [28-30], a key kinase in the signaling cascade of TNF through its TNF receptor 1 (TNFR1) (Figure 2A), were tested in vitro for their ability to reduce potency of L19-mTNF. Cytotoxicity assays were performed on the murine fibrosarcoma WEHI-164 cell line in the presence of actinomycin D, an inducer of the cell-cycle arrest at the G1-phase that prevents the overgrowth of the culture. All four tested inhibitors (GSK'963, GSK'2982772, Nec-1 and Nec1s) potently reduced TNF-mediated biocidal activity in a dose-dependent manner (Figure 2B). Inhibition of the biocidal TNF activity by RIPK1 small molecule inhibitors was confirmed also for L19-hTNF on the WEHI-164 cell line (Supplementary Figure 1). For further in vivo investigations, we decided to focus on the RIPK1specific inhibitor GSK'963, as this molecule was slightly 
more active in inhibiting the TNF-induced cytotoxicity effect $\left(\mathrm{IC}_{50}=79 \mathrm{pM}\right)$ as compared with the other tested inhibitors.

\section{GSK'963 does not inhibit the ability of L19- mTNF to induce pro-inflammatory cytokines production in vivo}

To characterize the immunological response to intravenously injected L19-mTNF, we measured plasma levels for a panel of relevant cytokines in immunocompetent tumor-free mice. L19-mTNF (given at the recommended dose of $250 \mu \mathrm{g} / \mathrm{Kg}$ ) potently induced high levels of proinflammatory cytokines (e.g., IL6, MCP-1 and TNF) already two hours after the injection, compared with the non-treated control group (Figure 3A). Pre-treatment with GSK'963 did not change the cytokine level profile, compared with the L19-mTNF monotherapy group. However, MCP-1 (monocyte chemoattractant protein 1) slightly decreased when animals were treated with combinatorial treatment of L19-mTNF and GSK'963 (p<0.01).

\section{GSK'963 does not interfere with tumor-specific vascular shut-down induced by L19-TNF}

To gain more insight on the effects of L19-mTNF on tumor and normal blood vessels, we collected healthy organs and tumor samples (CT-26 and WEHI-164) 24 hours after in vivo administration of the immunocytokine as single agent or in combination with GSK'963. Hoechst
33342 dye was perfused one minute prior to sacrifice, in order to assess variations in the perfusion and functionality of blood vessels. Vascular structures were detected by CD31 staining. Administration of L19-mTNF at the recommended dose of $250 \mu \mathrm{g} / \mathrm{Kg}$ (alone or combined with GSK'963) prevented penetration of the Hoechst dye in both CT-26 and WEHI-164 tumors, indicating the onset of a selective vascular shutdown in neoplastic lesions (Figure 3B). By contrast, no differences in vascular permeability were observed in kidney and liver between the different treatment groups (Figure 3C). Apoptotic cell death was detected in tumor and healthy organs (kidney and liver) by immunofluorescence staining of Caspase- 3 after the different treatments. Tumors treated either with L19-mTNF alone or in combination with GSK'963 were characterized by high number of dead cells (Caspase- 3 positive in green), in contrast with neoplastic samples excised from animals in the untreated group (PBS). Apoptosis was not detectable in healthy organs following L19-mTNF administration (Supplementary Figure 2).

\section{Pre-treatment with GSK'963 is compatible with in vivo selective tumor accumulation of L19-TNF}

The tumor-targeting performance of L19TNF in combination with GSK'963 was evaluated in immunocompetent 129/Sv mice bearing subcutaneouslygrafted F9 tumors, a well-established model to assess targeting properties of L19-based immunocytokines. L19hTNF was radiolabeled with ${ }^{125} \mathrm{I}$ and injected intravenously
A

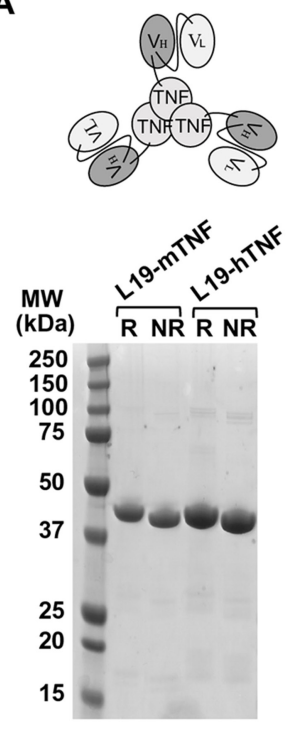

B

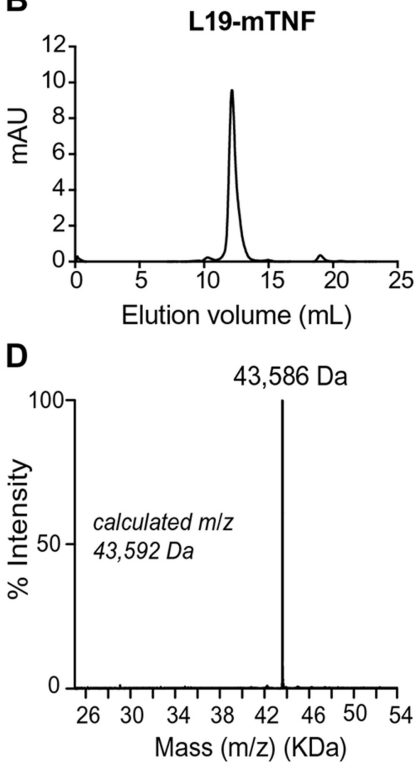

C

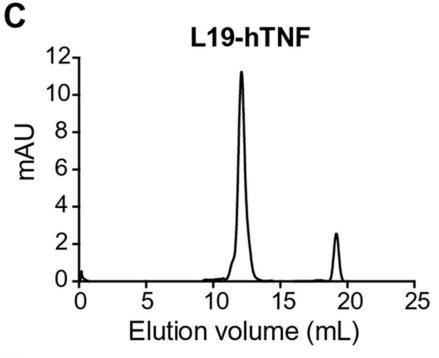

E

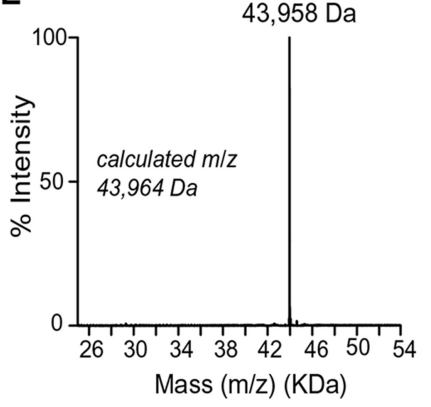

Figure 1: Quality control analyses of L19-TNF fusion proteins. (A) Schematic representation of L19-TNF and SDS-PAGE analysis. Size exclusion chromatography of L19-mTNF (B) and L19-hTNF (C) eluting after around 12 mL (elution volume); signals at around $19 \mathrm{~mL}$ are due to the presence of components of the formulation buffer that absorb UV light (i.e. salts with a small molecular size). (D, E) ESI-MS profile of L19-mTNF and of L19-hTNF, respectively. Abbreviations: MW, molecular weight; R, reducing conditions; NR, nonreducing conditions. 


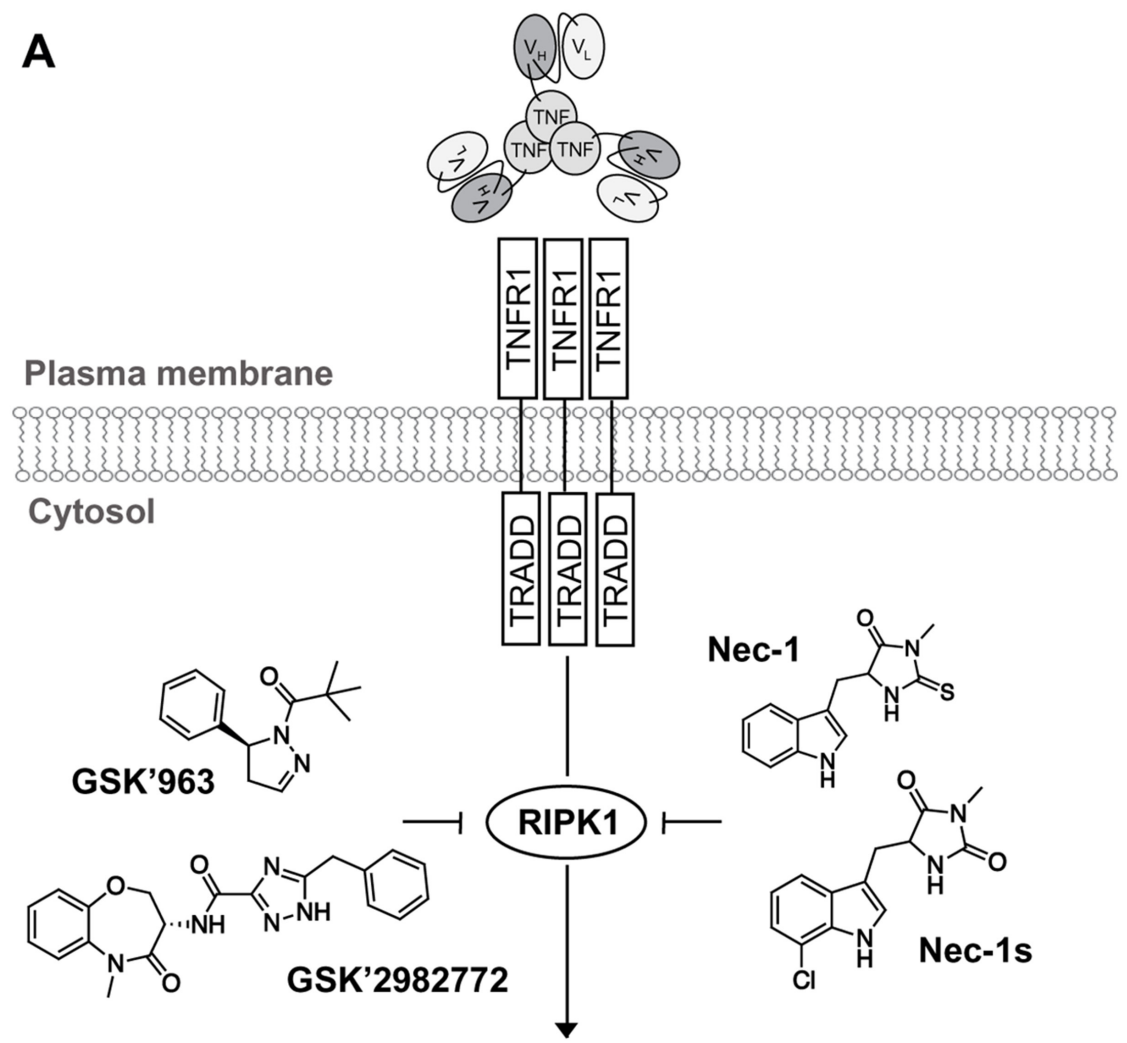

Cell survival, inflammation, apoptosis, necroptosis

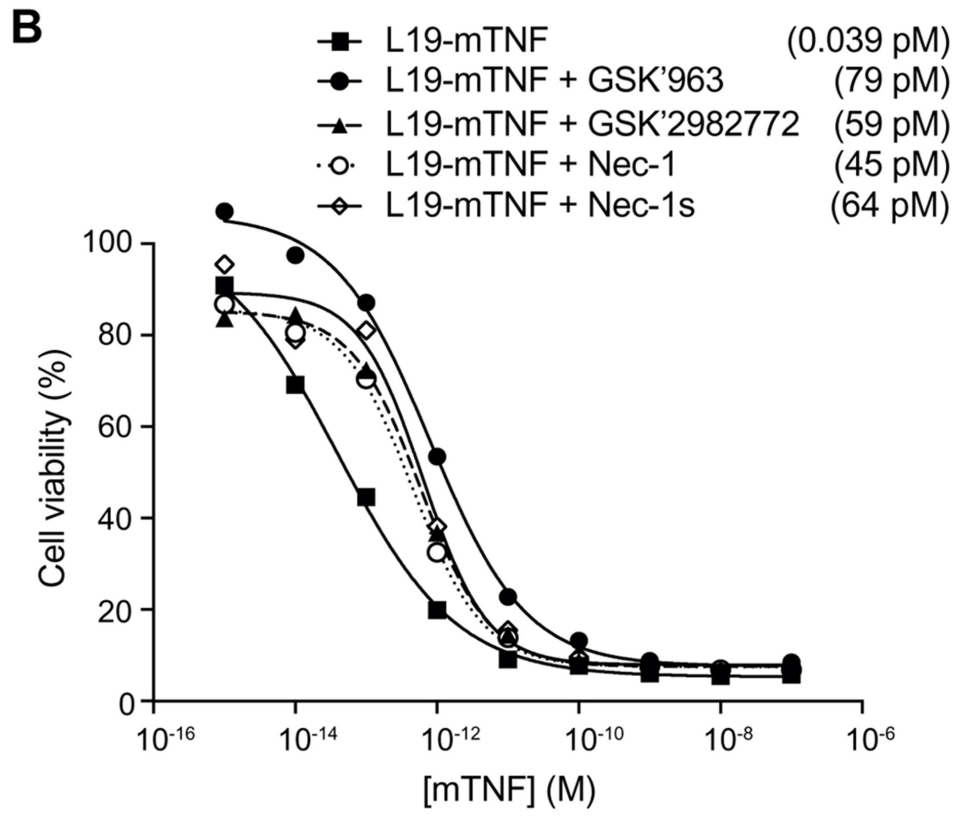

Figure 2: In vitro biocidal effect of L19-TNF. (A) Schematic representation of L19-TNF and TNFR1. The interaction between TNF and its receptor triggers a cascade of intracellular events which can be blocked by small molecule inhibitors of RIPK1 (structures of common RIPK1 inhibitors considered in this article are depicted). (B) In vitro activity of L19-mTNF alone or in combination with small molecule RIPK1 inhibitors. Dose-response curves of L19-mTNF ( $\square$ ) on WEHI-164 murine fibrosarcoma obtained in the presence or

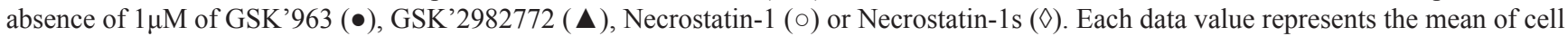
viability $\pm \mathrm{SD}(\mathrm{n}=3)$. In all cases, tested inhibitors of RIPK1 were able to reduce the killing activity of targeted-TNF. The potency of L19mTNF is expressed as calculated IC50 value in brackets. 
at the recommended dose of $250 \mu \mathrm{g} / \mathrm{Kg}$. L19-hTNF preferentially localized at the site of the disease, with a high tumor uptake value (18\% of the injected dose/gram of tissue; $\% \mathrm{ID} / \mathrm{g}$ ) and excellent tumor-to-normal organs ratio, 24 hours post-administration (i.e. average tumor-toorgans ratio 5.5:1 and tumor-to-blood ratio 4:1) (Figure 4). Pre-treatment with GSK'963 (2 mg/Kg; i.v. $30 \mathrm{~min}$ prior systemic administration of the immunocytokine) did not substantially alter the distribution profile of L19-TNF. While we have observed small differences in terms of absolute uptake in tumor and normal organs between the L19-TNF alone or in combination with the RIPK1 inhibitor GSK'963, the tumor-selectivity for the immunocytokine was preserved. These results motivated further investigation of the L19-TNF/GSK'963 combination in a therapy setting.

A

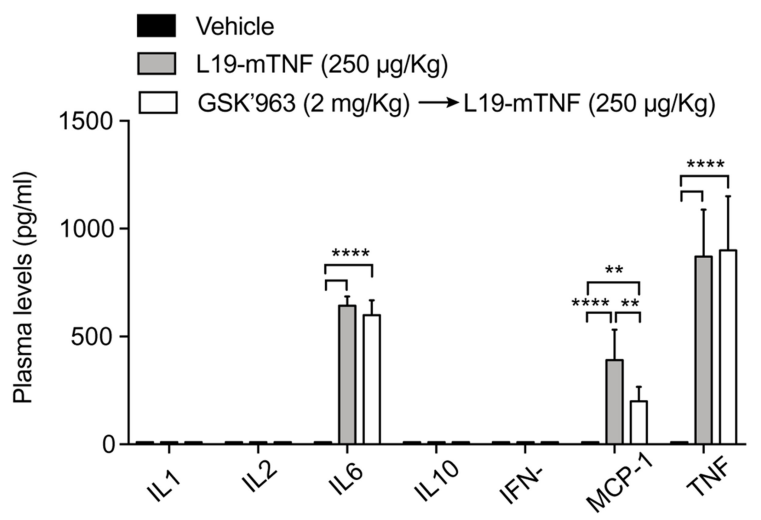

B
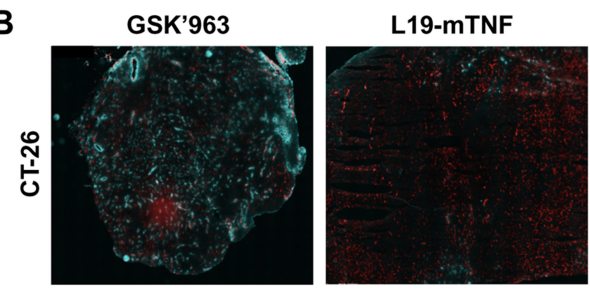

GSK'936 $\rightarrow$ L19-mTNF
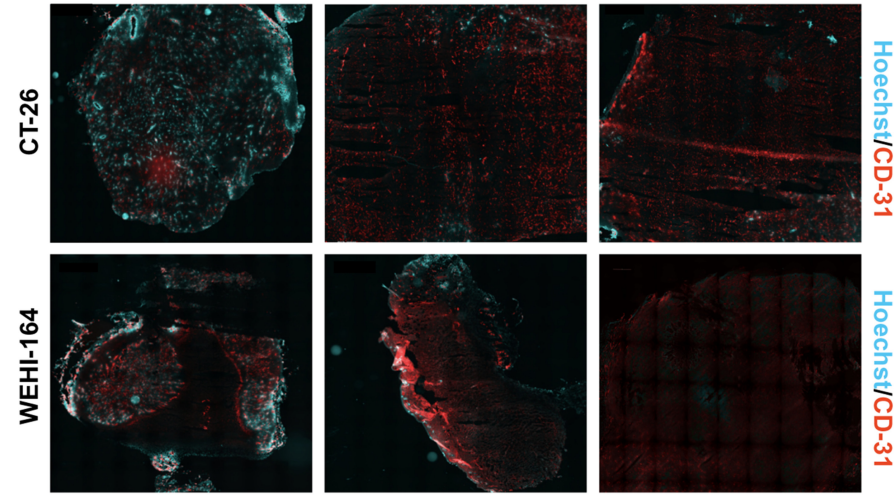

C

GSK'963

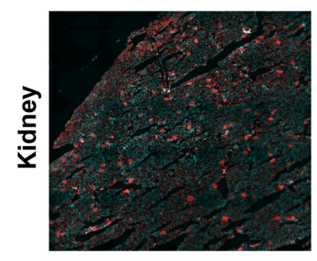

L19-mTNF
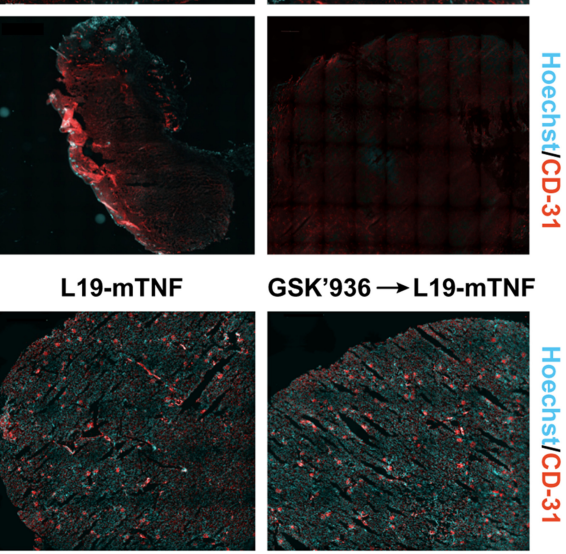

GSK'936 $\rightarrow$ L19-mTNF
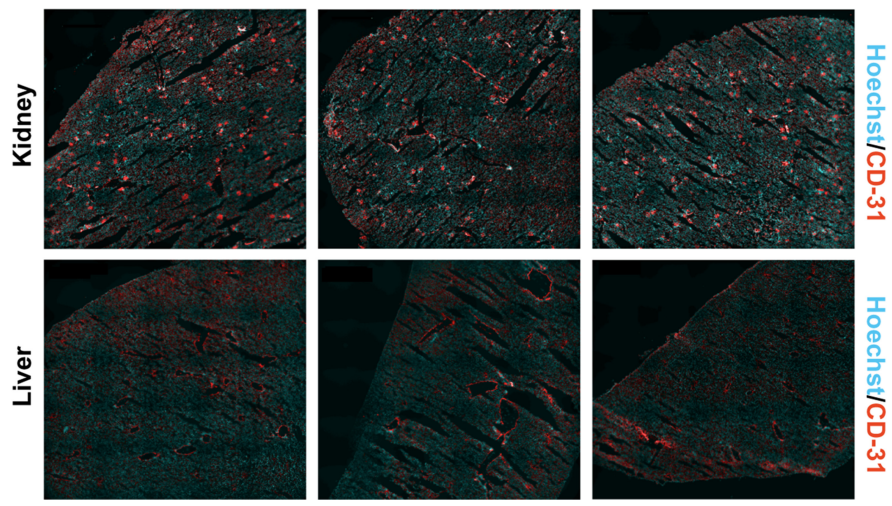

Figure 3: Determination of L19-mTNF effects on cytokine levels and vasculature in mice. The immunocytokine was given alone or in combination with the small molecule GSK'963, a potent small molecule inhibitor of RIPK1. (A) Quantification of plasma cytokine concentrations in immunocompetent BALB/c mice 2 hours after treatment with L19-mTNF. Data represent mean concentration values ( $\pm \mathrm{SD} ; \mathrm{n}=4$ mice per group). Statistical differences were evaluated between groups $\left({ }^{* * * *}, \mathrm{p} \leq 0.0001 ;{ }^{* *}, \mathrm{p} \leq 0.01\right)$. (B) Vascular permeability study in tumors (CT-26 and WEHI-164), healthy kidney and liver (C). Hoechst was injected i.v. 1 min before the sacrifice to analyze the permeability of tumor and organ vasculature. Pictures represent an overview obtained by stitching electronically adjacent regions of the samples $(20 \mathrm{x}$ magnification; scale bars $500 \mu \mathrm{m})$. Blue $=$ Hoechst staining; Red $=\mathrm{CD} 31$ vessels staining. 


\section{The therapeutic window of L19-TNF is improved by GSK'963}

In order to determine the maximum tolerated dose of L19-TNF in combination with GSK'963, we performed a therapy study in WEHI-164 tumor-bearing mice. This model was chosen based on the tumor sensitivity upon TNF treatment and, moreover, on the fact that the fullyhuman fusion protein is currently being studied in pivotal trials for soft-tissue sarcoma indication, in combination with doxorubicin (EudraCT 2016-003239-38 and NCT03420014). Animals were dosed systemically with L19-mTNF at 250 and $375 \mu \mathrm{g} / \mathrm{Kg}$, respectively. Two additional groups of animals were treated with GSK' 963 $(2 \mathrm{mg} / \mathrm{Kg}) 30 \mathrm{~min}$ before administration of L19-mTNF. Acute toxicity was evaluated by measuring daily changes in body weight. Effects on the body weigh lost after administration of L19-mTNF has been well characterized in previous studies [19, 31]. As predictable, L19-mTNF at the recommended dose $(250 \mu \mathrm{g} / \mathrm{Kg})$ caused reversible body weight loss $(<5 \%$, corresponding to moderate toxicity) (Figure 5A), while the high dose treatment (L19mTNF at $375 \mu \mathrm{g} / \mathrm{Kg}$ ) led to severe toxicity (body weight loss $>10 \%$ ) already 24 hours after the first administration (Figure 5B). Pre-administration of GSK'963 resulted in complete protection from TNF-induced body weight loss at the recommended dose of L19-mTNF (Figure 5A). Moreover, the severe acute toxicity induced by high dose of L19-mTNF was masked by pre-treatment with GSK'963, with increased overall survival of the animals (Figure 5B). The tumor volumes were measured along experiment in order to compare the anticancer activity of the different treatments. The use of a combinatorial setting with GSK'963 (Figure 5C and 5D) did not interfere with the therapeutic potential of the immunocytokine compared to monotherapy. In order to validate the rationale of using specific small-molecules inhibitors of the TNF intracellular signaling pathway, we replaced pre-treatment with GSK'963 by administration of the general antiinflammatory drug ibuprofen $(5 \mathrm{mg} / \mathrm{Kg}), 30 \mathrm{~min}$ prior to L19-mTNF injection ( $375 \mu \mathrm{g} / \mathrm{Kg})$. In this case, ibuprofen was not able to revert the severe body weight loss (Figure $5 \mathrm{E}$ and $5 \mathrm{~F}$ ) induced by administration of a high dose of L19-mTNF. The injected intravenous dose of ibuprofen was based on the referenced injectable solution Caldolor ${ }^{\circledR}$ (400-800 $\mathrm{mg}$ /injection corresponding to $5-10 \mathrm{mg} / \mathrm{Kg}$ in a $80 \mathrm{Kg}$ patient) [32].

\section{DISCUSSION}

We have described the use of a potent small molecule inhibitor of RIPK1 named GSK'963 for the improvement of the therapeutic window of an antibodyTNF fusion protein (L19-TNF) in preclinical models of cancer. Combination with GSK'963 enabled dose escalation of the immunocytokine beyond its MTD, while the single-dose administration of an equivalent amount of L19-TNF $(375 \mu \mathrm{g} / \mathrm{Kg})$ was found to be lethal. Inhibition of RIPK1 did not interfere with selective accumulation of L19-TNF into neoplastic lesions, where high local concentrations of TNF caused onset of tumor vascular shutdown and selective hemorrhagic necrosis. In contrast with these findings, pre-administration of ibuprofen at its recommended dose did not have a similar beneficial effect in reducing toxicities related to the administration of targeted-TNF.

TNF is a potent cytokine mediator of inflammation which is expressed by macrophages, NK cells, T cells, endothelial cells and fibroblasts [33, 34]. Trimeric TNF interacts with two different receptors, TNFR1

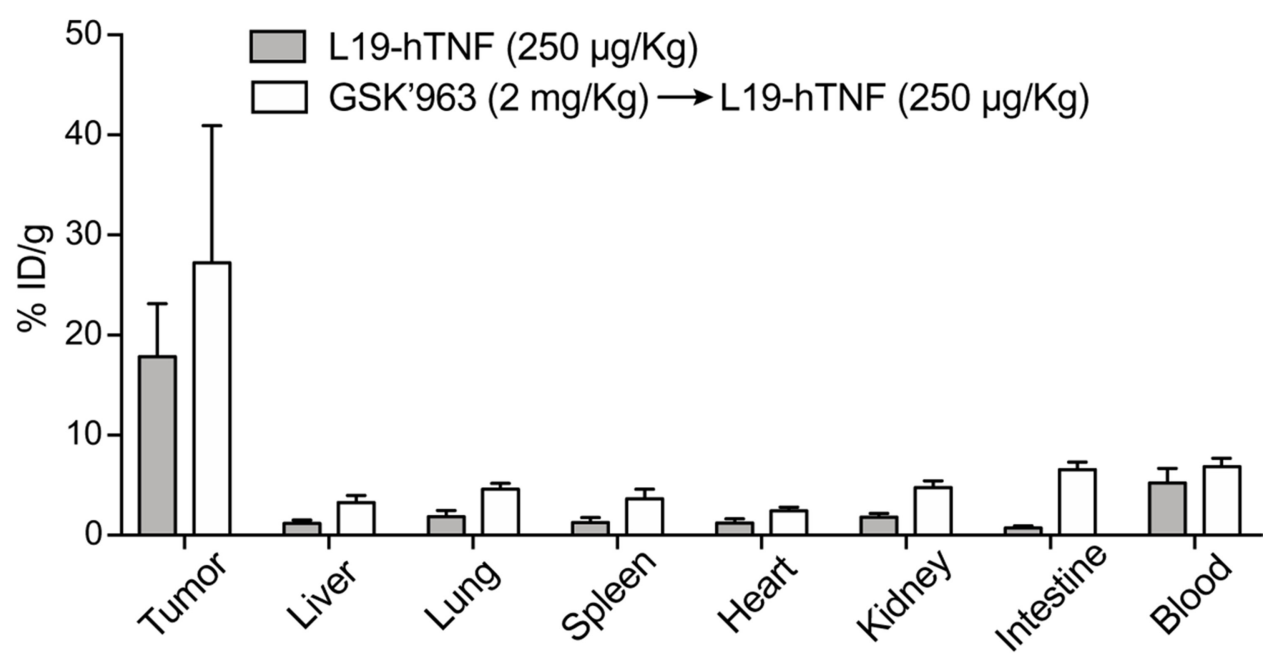

Figure 4: Biodistribution profile of targeted-TNF in F9 tumor-bearing mice. The immunocytokine was administered as monotherapy or in combination with GSK' 963 . Drug uptake values in tumors and healthy organs are expressed as percentage of the injected dose per gram of tissue (average; \% ID $/ \mathrm{g} \pm \mathrm{SD}$ ) measured 24 hours post-injection. 
A
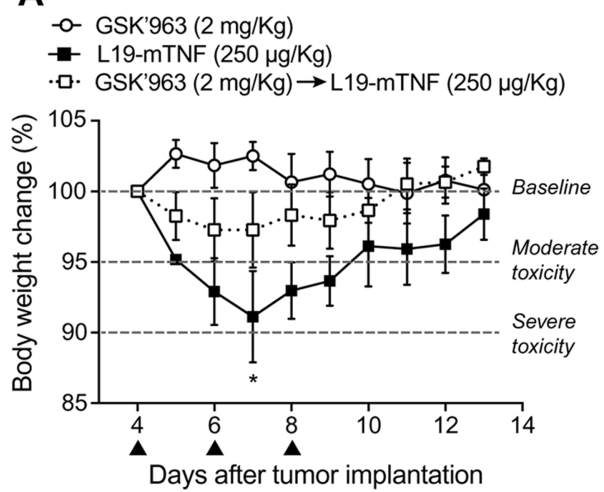

C

-o- GSK'963 (2 mg/Kg)

$\rightarrow$ L19-mTNF $(250 \mu \mathrm{g} / \mathrm{Kg})$

ㅁ. GSK'963 (2 mg/kg) $\rightarrow$ L19-mTNF $(250 \mu \mathrm{g} / \mathrm{Kg})$

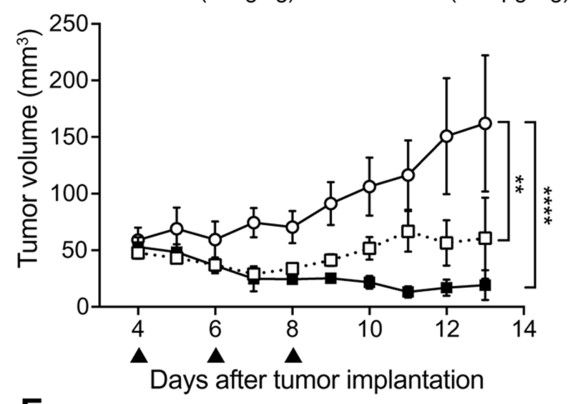

E
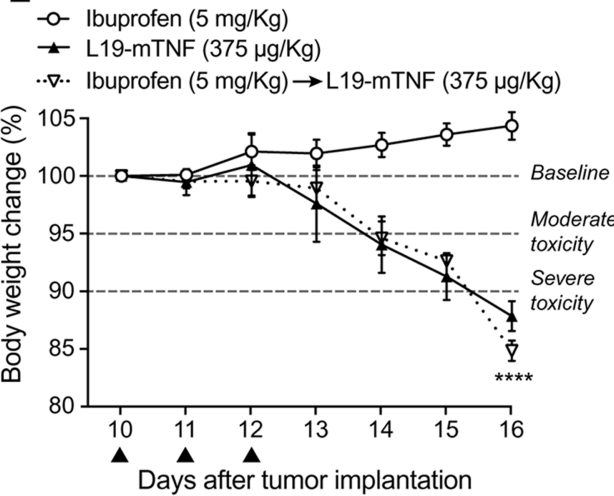

B

-o- GSK'963 (2 mg/Kg)

- L19-mTNF $(375 \mu \mathrm{g} / \mathrm{Kg})$

$\Delta \cdot$ GSK'963 $(2 \mathrm{mg} / \mathrm{Kg}) \rightarrow$ L19-mTNF $(375 \mu \mathrm{g} / \mathrm{Kg})$

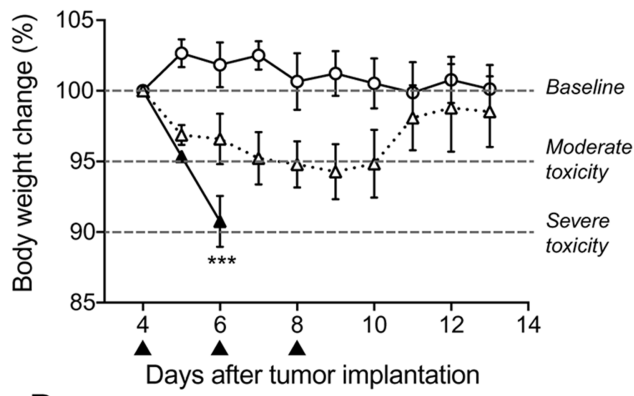

D

-o- GSK'963 (2 mg/Kg)

$\star$ L19-mTNF $(375 \mu \mathrm{g} / \mathrm{Kg})$

$. \Delta . \quad$ GSK'963 $(2 \mathrm{mg} / \mathrm{kg}) \rightarrow$ L19-mTNF $(375 \mu \mathrm{g} / \mathrm{Kg})$

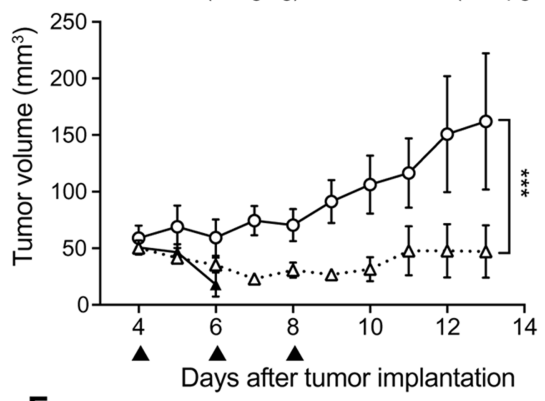

$\mathbf{F}$

-o- Ibuprofen $(5 \mathrm{mg} / \mathrm{Kg})$

$\neq \operatorname{L19-mTNF}(375 \mu \mathrm{g} / \mathrm{Kg})$

.. . . Ibuprofen $(5 \mathrm{mg} / \mathrm{Kg}) \rightarrow$ L19-mTNF $(375 \mu \mathrm{g} / \mathrm{Kg})$

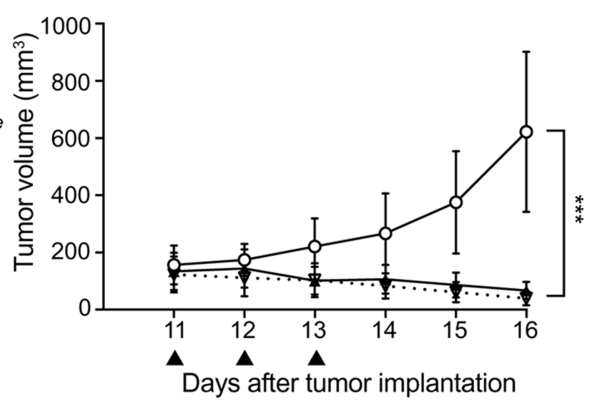

Figure 5: Tolerability and efficacy study in a syngeneic subcutaneous model of WEHI-164 fibrosarcoma. Different doses of L19-mTNF were given i.v. alone or in combination with GSK'963 ( $\boldsymbol{\Lambda}$ indicates i.v. administration of corresponding compounds). (A, B) Changes in animal body weight induced by treatments at the recommended $(250 \mu \mathrm{g} / \mathrm{Kg})$ and at a high $(375 \mu \mathrm{g} / \mathrm{Kg})$ dose of L19mTNF, respectively. (C, D) Plot of tumor volume measured daily and corresponding to different treatment groups. The same in vivo model was used to compare the L19-mTNF at high dose as a monotherapy or in a combinatorial setting with ibuprofen. Body weight changes (E) and tumor volume (F) were analyzed daily. Data represent mean of the experimental values ( \pm SEM; $\mathrm{n}=4$ mice per group). Statistical differences were assessed between treatment and control groups $\left.{ }^{(* * * *}, \mathrm{p} \leq 0.0001 ;{ }^{* * *}, \mathrm{p} \leq 0.001 ;{ }^{* *}, \mathrm{p} \leq 0.01 ;{ }^{*}, \mathrm{p} \leq 0.05\right)$.

and TNFR2, causing activation of complex signaling pathways that overall account for TNF-induced cell death, inflammation and cell activation [35]. Tissue degeneration and inflammation is mainly promoted by the interaction of TNF with TNFR1 and by subsequent recruitment and activation of the intra-cellular RIPK1 protein $[36,37]$.

The use of recombinant TNF has been previously proposed for cancer therapy, but significant toxicities and lack of efficacy prevented its clinical success for systemic application $[38,39]$. Hypotension, leukopenia, thrombocytopenia, fever, headache, nausea and hepatopathy represent the most common side effects detected in Phase II studies with recombinant TNF, while most serious toxicities include respiratory failure and coagulopathies [40]. Our group has previously demonstrated that the generation of antibody-TNF fusion proteins capable to selectively accumulate to tumors after systemic administration represents a valuable strategy to improve therapeutic window and efficacy of TNF [19-21]. L19-TNF is an antibody-fusion protein for the targeting 
of the alternatively-spliced EDB domain of fibronectin [41], that shows potent antitumor activity in preclinical models of cancer [13-15] and is now being investigated in clinical trials $[18,22,42]$. The product entered Phase III clinical trials in combination with L19-IL2 as neoadjuvant therapy prior to surgery of fully-resectable Stage IIIB, C melanoma (NCT02938299 and NCT03567889). Moreover, the combination of L19-TNF plus doxorubicin is being compared to doxorubicin monotherapy in pivotal trials as first-line treatment of advanced soft-tissue sarcoma (EudraCT 2016-003239-38 and NCT03420014).

While therapeutic activity can be dramatically improved by the selective delivery of cytokines to tumors via antibodies [19-21], toxicity profile is often similar to the one of unmodified cytokines. The majority of side effects of immunocytokines are typically observed in correspondence with the peak serum concentration of the product $[18,42]$. Transient symptoms including chills, fever, fatigue and pain are for example observed already few minutes after L19-TNF infusion in patients, with a peak around 1-2 hours after application and a total duration of few hours [42]. Pharmacological inhibition of cytokine activity shortly after intravenous administration represents an opportunity to improve the therapeutic window. Small molecules (like GSK'963) are particularly attractive for this application, since their serum halflife matches the clearance rate of recombinant antibody products from circulation [43] and inhibition of the cytokine activity may be harmonized with and prevent the onset of systemic side-effects of immunocytokines [28, 30]. GSK'963 is a small-molecule identified from a DNAencoded library described as a highly potent and selective inhibitor for the RIPK1 factor. Although can be considered an excellent tool compound to study RIPK1 inhibition, GSK'963 has not been further investigated in clinical studies due to its limited oral bioavailability in rodents [28]. A following lead optimization let to identify the new small-molecule GSK'2982778 with excellent preclinical and clinical pharmacokinetic properties [30], together with an accepted tolerability in healthy volunteers [44]. Several clinical trials are ongoing for the evaluation of the safety, tolerability and clinical efficacy of GSK'2982772 in patients with inflammatory disorders (rheumatoid arthritis: NCT02858492; ulcerative colitis: NCT02903966: plaquetype psoriasis: NCT02776033) [44].

We have successfully demonstrated that the MTD of L19-TNF can be increased by transient and selective inhibition of RIPK1, a key mediator of TNF-induced inflammation and tissue damage. Moreover, our results clearly show that small molecule inhibitors of RIPK1 are more effective in limiting the early toxicity of L19TNF, as compared to general anti-inflammatory drugs like ibuprofen that acts reducing pro-inflammatory cytokines secretion by inhibition of COX enzymes [45]. Our results may be of clinical relevance, as patients treated with L19TNF may benefit from judicious combinations with RIPK1 inhibitors, with potential improvement in terms of efficacy and safety of the treatment. Indeed, pharmacological approaches similar to the ones described in this article for L19-TNF may be applicable to other TNF-based pharmaceuticals or to other cytokine-based products. In particular, toxicities related to the administration of IL12or IL2-antibody products $[16,46,47]$ might benefit from the transient and selective inhibition of key intracellular mediators of their activity.

\section{MATERIALS AND METHODS}

\section{Compounds}

GSK'963 (Aobious), GSK'2982772, Necrostatin-1 and Necrostatin-1s (Nec-1 and Nec-1s; Selleck Chemicals) were dissolve in $100 \% \mathrm{DMSO}$ at $10 \mathrm{mg} / \mathrm{ml}$ and $\mathrm{kept}$ at $-20^{\circ} \mathrm{C}$ for long-term storage. Ibuprofen sodium (SigmaAldrich) was prepared at $5 \mathrm{mg} / \mathrm{ml}$ in deionized water and stored at $4^{\circ} \mathrm{C}$ for no longer than 1 week.

\section{Protein production}

L19-human TNF (L19-hTNF) is a fusion protein consisting of the L19 antibody in scFv format, sequentially fused to human TNF by the 17-amino-acid linker $\mathrm{EF}(\mathrm{SSSSG})_{3}$ [31]. The antibody-cytokine fusion protein was produced as GMP material by Philogen S.p.A (Siena, Italy) and dialyzed with cellulose membranes (Spectra/ Por $^{\circledR}$, Thermo Scientific) into phosphate-buffered saline (PBS; $20 \mathrm{mM} \mathrm{NaH} \mathrm{PO}_{4} ; 150 \mathrm{mM} \mathrm{NaCl}$; pH 7.4) prior biodistribution experiments.

L19-murine TNF (L19-mTNF) gene was cloned into the mammalian cell expression vector pcDNA3.1(+) (Invitrogen) by HindIII/NotI restriction sites. The L19mTNF fusion protein was expressed by transient gene expression in CHO-S cells and purified from the cell culture supernatant to homogeneity by protein A (Sino Biological) chromatography, as described previously [46]. After dialyses into PBS pH 7.4, the quality of the proteins was assessed by SDS-PAGE, by Sizeexclusion chromatography on a Superdex 200 Increase 10/300 GL column on an ÄKTA FPLC (GE Healthcare) and by mass spectrometry (Waters Xevo G2XS Q-TOF) (Supplementary Information).

\section{Cell lines}

Chinese Hamster Ovary cells (CHO-S; Invitrogen) were cultured in suspension in PowerCHO-2CD medium (Lonza), supplemented with Ultraglutamine-1 (4 mM; Lonza) and antibiotic-antimycotic (1\%; AA; Gibco).

Murine cells lines F9 (embryonal teratocarcinoma), WEHI-164 (fibrosarcoma) and CT-26 (colon carcinoma) were obtained from American Type Culture Collection. Cells were cultured in the corresponding medium 
supplemented with Fetal Bovine Serum (10\%; FBS; Invitrogen) and AA (1\%) following the supplier's protocol and kept in culture for no longer than 10 passages with a confluence lower than $90 \%$.

\section{In vitro cytotoxicity assay}

The direct killing activity of L19-mTNF was determined in vitro on the fibrosarcoma WEHI-164 cell line. Cells were seeded in 96-well plates (20'000 cells/ well) in RPMI-164 medium (Gibco). After 24 hours, new medium containing decreasing concentration of L19hTNF (1:10 dilution steps) with actinomycin D (Sigma; 2 $\mu \mathrm{g} / \mathrm{mL}$ ) was added to the cells, in the presence or absence of RIPK1 inhibitors (GSK'963, GSK'2982772, Nec-1 and Nec-1s; $1 \mu \mathrm{M})$. The cell viability was measured after 24 hours by adding $20 \mu$ of CellTiter 96® AQueous One Solution Reagent (Promega) directly to the wells. The number of living cells was determined by measuring the absorbance after 4 hours at $490 \mathrm{~nm}$ using Spark multimode microplate reader (Tecan). Experiments were performed in triplicate and the results were expressed as the percentage of cell viability compared with controls (cells treated with actinomycin D only).

\section{Animal experiments}

All the animal studies were conducted in accordance with Swiss animal welfare laws and regulations (license number ZH04/2018, granted by Veterinäramt des Kantons Zürich).

\section{Tumor implantation}

F9 cells were grown to $80 \%$ confluence and detached with Trypsin-EDTA $0.05 \%$ (Life Technologies). Cells were washed with Hank's Balanced Salt Solution (HBSS, pH 7.4) once, counted and re-suspended in HBSS to a final concentration of $6.7 \times 10^{7}$ cells $\mathrm{ml}^{-1}$. Aliquots of $10^{7}$ cells (150 $\mu$ l of suspension) were injected subcutaneously (s.c.) in the right flank of female $129 / \mathrm{Sv}$ mice (6-7 weeks of age, Janvier).

WEHI-164 and CT26 cells were grown to 80\% confluence and detached with Trypsin-EDTA $0.05 \%$ (Life Technologies). Cells were washed with Hank's Balanced Salt Solution (HBSS, pH 7.4) once, counted and re-suspended in HBSS to a final concentration of 1.7 $\times 10^{7}$ cells ml-1 . Aliquots of $2.5 \times 10^{6}$ cells $(150 \mu \mathrm{l}$ of a suspension) were injected s.c. in the right flank of female BALB/c mice (6-7 weeks of age, Janvier).

Tumor volume was determined with the following formula: $(d)^{2} \times D \times 0.52$, where $d$ and $D$ are the short and long dimensions in millimeters, respectively, measured with a caliper. Animals were sacrificed when termination criteria foreseen by the license were reached.

\section{Cytokine analyses in plasma}

Tumor-free BALB/c mice were injected intravenously (i.v.) with PBS, L19-mTNF $(250 \mu \mathrm{g} / \mathrm{Kg})$ or with GSK'963 (2 mg/Kg) followed by L19-mTNF $(250 \mu \mathrm{g} / \mathrm{Kg}$; $30 \mathrm{~min}$ later). After 2 hours, mice were euthanized and immediately exsanguinated. Blood was collected and incubated for $20 \mathrm{~min}$ in Microtainer tubes containing lithium heparin (BD Microtainer Tube). Plasma was obtained by centrifugation for $15 \mathrm{~min}$ at 3'000 rpm using a refrigerated centrifuge and stored at $-80^{\circ} \mathrm{C}$ prior to cytokine quantification.

IL2, IL6, IL10, MCP-1, IFN- $\gamma$, TNF and IL1 $\beta$ cytokine plasma levels were quantified using a multiplexed bead-based flow cytometric assay kit (Bio-Techne AG, Zug, Switzerland) following the described procedure [48] at the Cytolab facility (Regensdorf, Switzerland).

\section{Quantitative biodistribution experiment}

The in vivo targeting performance of L19-hTNF was evaluated in biodistribution studies as previously described [49]. Briefly, the immunocytokine was radioiodinated with ${ }^{125} \mathrm{I}$ (Hartmann Analytic) and Chloramine $\mathrm{T}$ hydrate $(0.25 \mu \mathrm{g} / \mu \mathrm{g}$ protein, Sigma) and purified on a PD10 column (GE Healthcare). Radiolabeled L19-hTNF $(250 \mu \mathrm{g} / \mathrm{Kg})$ was injected into the lateral tail vein of immunocompetent $129 / \mathrm{Sv}$ mice bearing s.c. implanted F9 teratocarcinoma. Alternatively, mice were pretreated with the RIPK1 inhibitor GSK'963 (2 mg/Kg) followed by i.v. injection of L19-hTNF ( $250 \mu \mathrm{g} / \mathrm{Kg} ; 30 \mathrm{~min}$ later). After 24 hours mice were sacrificed, organs were excised, weighed and the radioactivity of organs and tumors was counted using a Packard Cobra gamma counter. Radioactivity content of representative organs was expressed as the percentage of the injected dose per gram of tissue $(\% \mathrm{ID} / \mathrm{g})$.

\section{Therapy experiments}

WEHI-164 tumor-bearing BALB/c mice were randomized in groups of four and received three i.v. injections, once every second day. Mice were pretreated with either GSK'963 (2 $\mathrm{mg} / \mathrm{Kg})$ or ibuprofen at (5 $\mathrm{mg} / \mathrm{Kg}) 30 \mathrm{~min}$ prior to injection of L19-mTNF. Recommended $(250 \mu \mathrm{g} / \mathrm{Kg})$ or high $(375 \mu \mathrm{g} / \mathrm{Kg})$ doses of L19-mTNF were tested. Toxicity induced by murine TNF was monitored daily by checking the body weight of the animals. We considered a severe toxicity to be a more than $10 \%$ weight loss within 48 hours after a single intravenous injected dose, and an acceptable toxicity to be a lower than 5\% weight loss within 48 hours after a single intravenous injected dose. Tumors were measured with an electronic caliper to assess antitumor efficacy of the different treatments. Daily statistics are described in the Supplementary Information. 


\section{Immunofluorescence studies}

For the ex vivo detection of vascular permeability, WEHI-164 or CT-26 bearing BALB/c mice were injected i.v. with PBS, L19-mTNF $(250 \mu \mathrm{g} / \mathrm{Kg})$ or with GSK' 963 $(2 \mathrm{mg} / \mathrm{Kg})$ followed by L19-mTNF $(250 \mu \mathrm{g} / \mathrm{Kg} ; 30$ min later). After 24 hours, $10 \mathrm{mg} / \mathrm{Kg}$ of Hoechst 33342 (Thermo Scientific) was injected into the tail vein, and animals were euthanized after $1 \mathrm{~min}$. Tumor, kidney and liver were collected, embedded in cryoembedding medium (Thermo Scientific) and snap frozen in liquid nitrogen. Cryo-sections of $10 \mu \mathrm{m}$ were fixed in ice-cold acetone for $10 \mathrm{~min}$ and blocked for 1 hour in FBS (20\% solution in PBS). The vessels were stained with a rat anti-mouse CD31 (BD Pharmigen; 1:100) and with a donkey anti-rat Alexa Fluor 594 as a secondary antibody (Invitrogen; 1:500). Slides were mounted with fluorescent mounting medium (Dako, Glostrup, Denmark) and analyzed with Leica TIRF epi-fluorescence microscope (Scientific Center for Optical and Electron Microscopy ScopeM, ETH, Switzerland). Pictures representing a sample overview were obtained by stitching electronically adjacent regions.

\section{Statistics}

Data were analyzed using Prism 7.0 (GraphPad Software, Inc.). Student $t$ test was used to assess the differences of cell viability and of cytokine levels between different experimental groups. In therapy experiments, statistical significances were determined with a regular 2-way ANOVA test (with Bonferroni post-test; * ${ }^{*} \mathrm{p} \leq 0.05$; ${ }^{* *}, \mathrm{p} \leq 0.01 ;{ }^{* * *}, \mathrm{p} \leq 0.001 ;$ and $\left.{ }^{* * * *}, \mathrm{p} \leq 0.0001\right)$.

\section{Abbreviations}

AA: Antibiotic Antimycotic; ESI-ToFMS: Electrospray ionization time-of-flight Mass Spectrometry; FA: Formic Acid; FCS: Fetal Calf Serum; IC: Inhibitory Capacity; LC-MS: Liquid Chromatography-Mass Spectrometry; MeCN: Acetonitrile; MTS: 3-(4,5-dimethylthiazol-2-yl)5-(3-carboxymethylphenyl)-2-(4-sulfophenyl)-2Htetrazolium); PBS: Phosphate-Buffered saline; s.c., sub cutaneous; scFv: Single Chain Fragment Variable; SDS: Sodium Dodecyl Sulfate; TNFR: Tumor Necrosis Factor Receptor; UPLC: Ultra-Performance Liquid Chromatography.

\section{Author contributions}

Conception and Design of Study: SDP, MM, AV, DN, SC; Data collection: SDP, TO, BG, SC; Quality Control of Data: SDP, SC; Data analysis and interpretation: SDP, MM, AV, DN, SC; Statistical analysis: SDP; Manuscript preparation: SDP, DN, SC; Manuscript Review: SDP, TO, BG, DN, SC.

\section{ACKNOWLEDGMENTS}

The authors wish to thank Charlotte Howell for technical support in the production of L19-mTNF. The authors acknowledge support of the Scientific Center for Optical and Electron Microscopy ScopeM of the Swiss Federal Institute of Technology ETHZ. We personally acknowledge Justine Kusch for the help with microscopy. D.N. acknowledges funding from ETH Zurich, from the Swiss National Science Foundation (Grant Nr. 310030_182003/1) and from the European Research Council (ERC) under the European Union's Horizon 2020 research and innovation program (grant agreement 670603).

\section{CONFLICTS OF INTEREST}

Dario Neri is a co-founder and shareholder of Philogen (www.philogen.com), a Swiss-Italian Biotech company that operates in the field of ligand-based pharmacodelivery. Sheila Dakhel, Tiziano Ongaro, Baptiste Gouyou, Mattia Matasci, Alessandra Villa and Samuele Cazzamalli are employees of Philochem AG, daughter company of Philogen acting as discovery unit of the group.

\section{FUNDING}

D.N. acknowledges funding from ETH Zurich. This project has received funding from the Swiss National Science Foundation (Grant Nr. 310030_182003/1) and the European Research Council (ERC) under the European Union's Horizon 2020 research and innovation program (grant agreement 670603).

\section{REFERENCES}

1. Yamazaki N, Takenouchi T, Fujimoto M, Ihn H, Uchi H, Inozume T, Kiyohara Y, Uhara H, Nakagawa K, Furukawa H, Wada H, Noguchi K, Shimamoto T, Yokota K. Phase 1b study of pembrolizumab (MK-3475; anti-PD-1 monoclonal antibody) in Japanese patients with advanced melanoma (KEYNOTE-041). Cancer Chemother Pharmacol. 2017; 79: 651-60. https://doi.org/10.1007/s00280-016-3237-x. [PubMed]

2. Goldberg SB, Gettinger SN, Mahajan A, Chiang AC, Herbst RS, Sznol M, Tsiouris AJ, Cohen J, Vortmeyer A, Jilaveanu L, Yu J, Hegde U, Speaker S, et al. Pembrolizumab for patients with melanoma or non-small-cell lung cancer and untreated brain metastases: early analysis of a non-randomised, open-label, phase 2 trial. Lancet Oncol. 2016; 17: 976-83. https://doi.org/10.1016/S1470-2045(16)30053-5 [PubMed]

3. Nanda R, Chow LQ, Dees EC, Berger R, Gupta S, Geva R, Pusztai L, Pathiraja K, Aktan G, Cheng JD, Karantza 
V, Buisseret L. Pembrolizumab in patients with advanced triple-negative breast cancer: phase Ib keynote-012 study. J Clin Oncol. 2016; 34: 2460-67. https://doi.org/10.1200/ JCO.2015.64.8931. [PubMed]

4. Hutmacher C, Neri D. Antibody-cytokine fusion proteins: biopharmaceuticals with immunomodulatory properties for cancer therapy. Adv Drug Deliv Rev. 2019; 141: 67-91. https://doi.org/10.1016/j.addr.2018.09.002. [PubMed]

5. Fyfe G, Fisher RI, Rosenberg SA, Sznol M, Parkinson DR, Louie AC. Results of treatment of 255 patients with metastatic renal cell carcinoma who received high-dose recombinant interleukin-2 therapy. J Clin Oncol. 1995; 13: 688-96. https://doi.org/10.1200/JCO.1995.13.3.688. [PubMed]

6. Fisher RI, Rosenberg SA, Fyfe G. Long-term survival update for high-dose recombinant interleukin-2 in patients with renal cell carcinoma. Cancer J Sci Am. 2000; 6: S5557. [PubMed]

7. Eggermont AM, Schraffordt Koops H, Liénard D, Kroon BB, van Geel AN, Hoekstra HJ, Lejeune FJ. Isolated limb perfusion with high-dose tumor necrosis factor- $\alpha$ in combination with interferon- $\gamma$ and melphalan for nonresectable extremity soft tissue sarcomas: a multicenter trial. J Clin Oncol. 1996; 14: 2653-65. https://doi. org/10.1200/JCO.1996.14.10.2653. [PubMed]

8. Lejeune FJ, Liénard D, Matter M, Rüegg C. Efficiency of recombinant human TNF in human cancer therapy. Cancer Immun. 2006; 6: 6. [PubMed]

9. Neri D. Antibody-Cytokine Fusions: Versatile Products for the Modulation of Anticancer Immunity. Cancer Immunol Res. 2019; 7: 348-54. https://doi.org/10.1158/2326-6066. CIR-18-0622. [PubMed]

10. Kontermann RE. Antibody-cytokine fusion proteins. Arch Biochem Biophys. 2012; 526: 194-205. https://doi. org/10.1016/j.abb.2012.03.001. [PubMed]

11. Xiang R, Lode HN, Dreier T, Gillies SD, Reisfeld RA. Induction of persistent tumor-protective immunity in mice cured of established colon carcinoma metastases. Cancer Res. 1998; 58: 3918-25. [PubMed]

12. Khawli LA, Miller GK, Epstein AL. Effect of seven new vasoactive immunoconjugates on the enhancement of monoclonal antibody uptake in tumors. Cancer. 1994; 73: 824-31. [PubMed]

13. Hemmerle T, Neri D. The antibody-based targeted delivery of interleukin-4 and 12 to the tumor neovasculature eradicates tumors in three mouse models of cancer. Int J Cancer. 2014; 134: 467-77. https://doi.org/10.1002/ ijc.28359. [PubMed]

14. Schwager K, Hemmerle T, Aebischer D, Neri D. The immunocytokine L19-IL2 eradicates cancer when used in combination with CTLA-4 blockade or with L19TNF. J Invest Dermatol. 2013; 133: 751-58. https://doi. org/10.1038/jid.2012.376. [PubMed]
15. Halin C, Gafner V, Villani ME, Borsi L, Berndt A, Kosmehl H, Zardi L, Neri D. Synergistic therapeutic effects of a tumor targeting antibody fragment, fused to interleukin 12 and to tumor necrosis factor $\alpha$. Cancer Res. 2003; 63:320210. [PubMed]

16. Weide B, Eigentler TK, Pflugfelder A, Zelba H, Martens A, Pawelec G, Giovannoni L, Ruffini PA, Elia G, Neri D, Gutzmer R, Becker JC, Garbe C. Intralesional treatment of stage III metastatic melanoma patients with L19-IL2 results in sustained clinical and systemic immunologic responses. Cancer Immunol Res. 2014; 2: 668-78. https:// doi.org/10.1158/2326-6066.CIR-13-0206. [PubMed]

17. Eigentler TK, Weide B, de Braud F, Spitaleri G, Romanini A, Pflugfelder A, González-Iglesias R, Tasciotti A, Giovannoni L, Schwager K, Lovato V, Kaspar M, Trachsel $\mathrm{E}$, et al. A dose-escalation and signal-generating study of the immunocytokine L19-IL2 in combination with dacarbazine for the therapy of patients with metastatic melanoma. Clin Cancer Res. 2011; 17: 7732-42. https://doi. org/10.1158/1078-0432.CCR-11-1203. [PubMed]

18. Danielli R, Patuzzo R, Di Giacomo AM, Gallino G, Maurichi A, Di Florio A, Cutaia O, Lazzeri A, Fazio C, Miracco C, Giovannoni L, Elia G, Neri D, et al. Intralesional administration of L19-IL2/L19-TNF in stage III or stage IVM1 a melanoma patients: results of a phase II study. Cancer Immunol Immunother. 2015; 64: 999-1009. https://doi.org/10.1007/s00262-015-1704-6. [PubMed]

19. De Luca R, Soltermann A, Pretto F, Pemberton-Ross C, Pellegrini G, Wulhfard S, Neri D. Potency-matched Dual Cytokine-Antibody Fusion Proteins for Cancer Therapy. Mol Cancer Ther. 2017; 16: 2442-51. https://doi. org/10.1158/1535-7163.MCT-17-0211. [PubMed]

20. Hemmerle T, Probst P, Giovannoni L, Green AJ, Meyer T, Neri D. The antibody-based targeted delivery of TNF in combination with doxorubicin eradicates sarcomas in mice and confers protective immunity. Br J Cancer. 2013; 109: 1206-13. https://doi.org/10.1038/bjc.2013.421 [PubMed].

21. Probst P, Kopp J, Oxenius A, Colombo MP, Ritz D, Fugmann T, Neri D. Sarcoma eradication by doxorubicin and targeted TNF relies upon CD8 + T-cell recognition of a retroviral antigen. Cancer Res. 2017; 77: 3644-54. https:// doi.org/10.1158/0008-5472.CAN-16-2946. [PubMed]

22. Papadia F, Basso V, Patuzzo R, Maurichi A, Di Florio A, Zardi L, Ventura E, González-Iglesias R, Lovato V, Giovannoni L, Tasciotti A, Neri D, Santinami M, et al. Isolated limb perfusion with the tumor-targeting human monoclonal antibody-cytokine fusion protein L19-TNF plus melphalan and mild hyperthermia in patients with locally advanced extremity melanoma. J Surg Oncol. 2013; 107: 173-79. https://doi.org/10.1002/jso.23168. [PubMed]

23. Sabel MS, Arora A, Su G, Mathiowitz E, Reineke JJ, Chang AE. Synergistic effect of intratumoral IL-12 and TNF- $\alpha$ microspheres: systemic anti-tumor immunity is mediated by both CD8+ CTL and NK cells. Surgery. 2007; 142: 749-60. https://doi.org/10.1016/j.surg.2007.05.008. [PubMed] 
24. Lienard D, Ewalenko P, Delmotte JJ, Renard N, Lejeune FJ. High-dose recombinant tumor necrosis factor alpha in combination with interferon gamma and melphalan in isolation perfusion of the limbs for melanoma and sarcoma. J Clin Oncol. 1992; 10: 52-60. https://doi.org/10.1200/ JCO.1992.10.1.52. [PubMed]

25. Feinberg B, Kurzrock R, Talpaz M, Blick M, Saks S, Gutterman JU. A phase I trial of intravenously-administered recombinant tumor necrosis factor-alpha in cancer patients. J Clin Oncol. 1988; 6: 1328-34. https://doi.org/10.1200/ JCO.1988.6.8.1328. [PubMed]

26. Kondylis V, Pasparakis M. RIP Kinases in Liver Cell Death, Inflammation and Cancer. Trends Mol Med. 2019; 25: 47-63. https://doi.org/10.1016/j.molmed.2018.10.007. [PubMed]

27. Amin P, Florez M, Najafov A, Pan H, Geng J, Ofengeim D, Dziedzic SA, Wang H, Barrett VJ, Ito Y, LaVoie MJ, Yuan J. Regulation of a distinct activated RIPK1 intermediate bridging complex I and complex II in TNF $\alpha$-mediated apoptosis. Proc Natl Acad Sci USA. 2018; 115: E5944-53. https://doi.org/10.1073/pnas.1806973115. [PubMed]

28. Berger SB, Harris P, Nagilla R, Kasparcova V, Hoffman S, Swift B, Dare L, Schaeffer M, Capriotti C, Ouellette M, King BW, Wisnoski D, Cox J, et al. Characterization of GSK'963: a structurally distinct, potent and selective inhibitor of RIP1 kinase. Cell Death Discov. 2015; 1: 15009. https://doi.org/10.1038/cddiscovery.2015.9. [PubMed]

29. Degterev A, Hitomi J, Germscheid M, Ch'en IL, Korkina O, Teng X, Abbott D, Cuny GD, Yuan C, Wagner G, Hedrick SM, Gerber SA, Lugovskoy A, Yuan J. Identification of RIP1 kinase as a specific cellular target of necrostatins. Nat Chem Biol. 2008; 4: 313-21. https://doi.org/10.1038/ nchembio.83. [PubMed]

30. Harris PA, Berger SB, Jeong JU, Nagilla R, Bandyopadhyay D, Campobasso N, Capriotti CA, Cox JA, Dare L, Dong $\mathrm{X}$, Eidam PM, Finger JN, Hoffman SJ, et al. Discovery of a First-in-Class Receptor Interacting Protein 1 (RIP1) Kinase Specific Clinical Candidate (GSK2982772) for the Treatment of Inflammatory Diseases. J Med Chem. 2017; 60: 1247-61. https://doi.org/10.1021/acs. jmedchem.6b01751. [PubMed]

31. Borsi L, Balza E, Carnemolla B, Sassi F, Castellani P, Berndt A, Kosmehl H, Biro A, Siri A, Orecchia P, Grassi J, Neri D, Zardi L. Selective targeted delivery of TNFalpha to tumor blood vessels. Blood. 2003; 102: 4384-92. https:// doi.org/10.1182/blood-2003-04-1039. [PubMed]

32. Bookstaver B, Miller AD, Rudisill C, Norris L. Intravenous ibuprofen: the first injectable product for the treatment of pain and fever. J Pain Res. 2010; 3: 67-79. https://doi. org/10.2147/JPR.S6993.

33. Sedger LM, McDermott MF. TNF and TNF-receptors: from mediators of cell death and inflammation to therapeutic giants - past, present and future. Cytokine Growth
Factor Rev. 2014; 25: 453-72. https://doi.org/10.1016/j. cytogfr.2014.07.016. [PubMed]

34. Falvo JV, Tsytsykova AV, Goldfeld AE. Transcriptional control of the TNF gene. TNF Pathophysiology. Molecular and Cellular Mechanisms. Curr Dir Autoimmun. Basel, Karger. 2010; 11: 27-60. https://doi. org/10.1159/000289196.

35. Kalliolias GD, Ivashkiv LB. TNF biology, pathogenic mechanisms and emerging therapeutic strategies. Nat Rev Rheumatol. 2016; 12: 49-62. https://doi.org/10.1038/ nrrheum.2015.169. [PubMed]

36. Brenner C, Galluzzi L, Kepp O, Kroemer G. Decoding cell death signals in liver inflammation. J Hepatol. 2013; 59:583-94. $\quad$ https://doi.org/10.1016/j.jhep.2013.03.033. [PubMed]

37. Sheridan C. Death by inflammation: drug makers chase the master controller. Nat Biotechnol. 2019; 37: 111-13. https:// doi.org/10.1038/s41587-019-0023-4. [PubMed]

38. Creaven PJ, Brenner DE, Cowens JW, Huben RP, Wolf RM, Takita H, Arbuck SG, Razack MS, Proefrock AD. A phase I clinical trial of recombinant human tumor necrosis factor given daily for five days. Cancer Chemother Pharmacol. 1989; 23: 186-91. https://doi.org/10.1007/BF00267953. [PubMed].

39. Gamm H, Lindemann A, Mertelsmann R, Herrmann F. Phase I trial of recombinant human tumour necrosis factor $\alpha$ in patients with advanced malignancy. Eur J Cancer. 1991; 27: 856-63. https://doi.org/10.1016/0277-5379(91)90134-Y. [PubMed]

40. Lenk H, Tanneberger S, Müller U, Ebert J, Shiga T. Phase II clinical trial of high-dose recombinant human tumor necrosis factor. Cancer Chemother Pharmacol. 1989; 24:391-92. https://doi.org/10.1007/BF00257449. [PubMed]

41. Birchler M, Viti F, Zardi L, Spiess B, Neri D. Selective targeting and photocoagulation of ocular angiogenesis mediated by a phage-derived human antibody fragment. Nat Biotechnol. 1999; 17: 984-88. https://doi. org/10.1038/13679. [PubMed]

42. Spitaleri G, Berardi R, Pierantoni C, De Pas T, Noberasco C, Libbra C, González-Iglesias R, Giovannoni L, Tasciotti A, Neri D, Menssen HD, de Braud F. Phase I/II study of the tumour-targeting human monoclonal antibody-cytokine fusion protein L19-TNF in patients with advanced solid tumours. J Cancer Res Clin Oncol. 2013; 139: 447-55. https://doi.org/10.1007/s00432-012-1327-7. [PubMed].

43. Oo C, Kalbag SS. Leveraging the attributes of biologics and small molecules, and releasing the bottlenecks: a new wave of revolution in drug development. Expert Rev Clin Pharmacol. 2016; 9: 747-49. https://doi.org/10.1586/17512 433.2016.1160778. [PubMed]

44. Weisel K, Scott NE, Tompson DJ, Votta BJ, Madhavan S, Povey K, Wolstenholme A, Simeoni M, Rudo T, Richards-Peterson L, Sahota T, Wang JG, Lich J, et al. Randomized clinical study of safety, pharmacokinetics, 
and pharmacodynamics of RIPK1 inhibitor GSK2982772 in healthy volunteers. Pharmacol Res Perspect. 2017; 5: e00365. https://doi.org/10.1002/prp2.365. [PubMed]

45. Albuquerque AF, Fonteles CS, do Val DR, Chaves HV, Bezerra MM, Pereira KM, de Barros Silva PG, de Lima BB, Soares EC, Ribeiro TR, Costa FW. Effect of pre-emptive analgesia on clinical parameters and tissue levels of TNF- $\alpha$ and IL-1 $\beta$ in third molar surgery: a triple-blind, randomized, placebocontrolled study. Int J Oral Maxillofac Surg. 2017; 46: 161525. https://doi.org/10.1016/j.ijom.2017.05.007. [PubMed]

46. Ongaro T, Matasci M, Cazzamalli S, Gouyou B, De Luca R, Neri D, Villa A. A novel anti-cancer L19-interleukin-12 fusion protein with an optimized peptide linker efficiently localizes in vivo at the site of tumors. J Biotechnol. 2019; 291: 17-25. https://doi.org/10.1016/j.jbiotec.2018.12.004. [PubMed]
47. Strauss J, Heery CR, Kim JW, Jochems C, Donahue RN, Montgomery AS, McMahon S, Lamping E, Marté JL, Madan RA, Bilusic M, Silver MR, Bertotti E, et al. First-in-human phase I trial of a tumor-targeted cytokine (NHS-IL12) in subjects with metastatic solid tumors. Clin Cancer Res. 2019; 25: 99-109. https://doi.org/10.1158/1078-0432.CCR-18-1512. [PubMed]

48. Vignali DA. Multiplexed particle-based flow cytometric assays. J Immunol Methods. 2000; 243: 243-55. https://doi. org/10.1016/S0022-1759(00)00238-6. [PubMed]

49. Venetz D, Hess C, Lin CW, Aebi M, Neri D. Glycosylation profiles determine extravasation and disease-targeting properties of armed antibodies. Proc Natl Acad Sci USA. 2015; 112: 2000-05. https://doi.org/10.1073/pnas.1416694112. [PubMed] 